\title{
Correction to: In silico evaluation and in vitro growth inhibition of Plasmodium falciparum by natural amides and synthetic analogs
}

\section{Minelly Azevedo da Silva ${ }^{1,2,3}$ • Márcia Paranho Veloso ${ }^{4,5} \cdot$ Kassius de Souza Reis ${ }^{4,5}$ - Guilherme Matos Passarini ${ }^{1,3,6}$. Ana Paula de Azevedo dos Santos ${ }^{1,3,6}$. Leandro do Nascimento Martinez ${ }^{1,3,6}$. Harold Hilarion Fokoue ${ }^{7}$. Massuo Jorge Kato ${ }^{7}$. Carolina Bioni Garcia Teles ${ }^{1,3,6,8}$. Christian Collins Kuehn ${ }^{1,3}$}

Published online: 21 May 2020

(C) Springer-Verlag GmbH Germany, part of Springer Nature 2020

\section{Correction to: Parasitol Res}

https://doi.org/10.1007/s00436-020-06681-9

The original version of the article above contained an error in the text. The phrase 'The $\mathrm{S}$ scale (solubility Table 1) classifies the solubility of compounds in water as insoluble for values below 10; slightly soluble $<6$; moderately soluble $<4$; soluble $<2$; very soluble $<0$ (Guerra 2019). The S (solubility) values of natural compounds 1a (piplartine) and 18a (piperine) were 2.39 and - 3.61, respectively.' should be replaced by 'The S scale (solubility - Table 1) classifies the solubility of the compounds in water. insoluble in water. Values less than $<-10$; slightly soluble $<-6$; moderately soluble $<-4$; soluble <- 2; very soluble <0 (Guerra 2019; OSIRIS Property explorer). The S (solubility) values for natural compounds $1 \mathrm{a}$ (piplartine) and $18 \mathrm{a}$ (piperine) were - 2.39 and - 3.61, respectively'.

Another error is that the spelling of Guilherme de Matos Passarini name is incorrect. The correct spelling is Guilherme Matos Passarini.

Publisher's note Springer Nature remains neutral with regard to jurisdictional claims in published maps and institutional affiliations.

The online version of the original article can be found at https://oi.org/ 10.1007/s00436-020-06681-9

Minelly Azevedo da Silva

minelly.silva@ifro.edu.br

1 Programa de Pós graduação em Biologia Experimental, PGBIOEXP, Porto Velho, Brazil

2 Instituto Federal de Rondônia, IFRO, Porto Velho, Rondônia, Brazil

3 Universidade Federal de Rondônia - UNIR, Porto Velho, Brazil

4 Laboratório de Avaliação e de Síntese de Substâncias Bioativas, Alfenas, MG, Brazil

5 Universidade Federal de Alfenas, Alfenas, MG, Brazil

6 Fundação Oswaldo Cruz, Rondônia (FIOCRUZ -RO) / EpiAmO, Porto Velho, Brazil

7 Instituto de Química da Universidade de São Paulo, IQ-USP, São Paulo, Brazil

8 Centro Universitário São Lucas, UniSL, Porto Velho, Brazil 